\title{
La invención de la selva austral. Bosques y tierras despejadas en la cuenca del río Valdivia (siglos XVI-XIX) ${ }^{1}$
}

\author{
Pablo Camus², María Eugenia Solari ${ }^{3}$
}

\begin{abstract}
RESUMEN
Este trabajo estudia las relaciones entre los bosques y las tierras despejadas en la región valdiviana entre los siglo XVI y XIX, entendiendo que esta interacción indica espacios antropizados que dan cuenta de poblaciones humanas interviniendo los bosques con el objeto de habilitar territorios aptos para realizar prácticas agrícolas y ganaderas. En la cuenca de río Valdivia, desde el Holoceno medio (3.000 A.P.) hasta mediados del siglo XIX, predominó el bosque como componente fundamental del ambiente. Desde la Conquista fue perceptible el aumento progresivo de los bosques en relación con las tierras despejadas dispuestas para la agricultura u otras actividades humanas desde el río Toltén hacia el sur. No obstante, en el siglo XVI había menos bosque y más zonas despejadas y pobladas que en el siglo XIX y parte de la exuberante vegetación encontrada por los viajeros y exploradores de entonces tenía poco más de dos siglos de existencia, pues el descenso demográfico provocado por la conquista y colonización, sumado a un cambio en la estrategia de habitar el territorio, tanto por las comunidades autóctonas como alóctonas, habría permitido el avance de los bosques en la región durante los siglos XVII y XVIII.
\end{abstract}

Palabras clave: Geografía histórica, historia ambiental, gestión de bosques.

\begin{abstract}
This project studies the relationship between cleared forests and lands in the Valdivia region during the 16th and 19th century, understanding that this interaction indicates intervened spaces; human population intervening these forests with aims of making the territory suitable for agriculture and ranching. Since the middle Holocene until the middle of the 19th century, the Valdivia River basin had forests as a main component of its environment. Since the Conquista there was a progressive increase of forests in comparison with cleared lands arranged for agriculture or other human activities from the Tolten River towards south. Nonetheless during the 16th century there was less forest and more cleared and populated areas than in the 19th century and part of the exuberant vegetation found by the voyagers and explorers had less than two centuries of existence due to the demographic decrease forced by the Conquista and the colonization. Moreover there was a strategic change in the form of inhabiting the territory not only by native communities but also by foreign ones, which would have allowed the increase of forests in the region during the 17 th and 18 th centuries.
\end{abstract}

Key words: Historical geography, environmental history, forest management.

\footnotetext{
1 Esta investigación se inserta dentro del Fondecyt 1040326 "Dinámica ocupacional y ambiental de los bosques templados del sur de Chile: estudio interdisciplinario de la cuenca de Valdivia durante los periodos arcaico y transición formativo". Una versión resumida de este trabajo fue presentada al XVI Congreso de Arqueología Chilena (Valdivia, octubre 2006) y aparecerá en sus actas bajo el título de "Construyendo la Historia Ambiental de la
}

Cuenca del Río Valdivia (SIGLOS XVI-XIX)". Artículo recibido el 21 de agosto de 2007 y aceptado el 6 de marzo de 2008.

2 Centro de Estudios Avanzados en Ecología y Biodiversidad. Universidad Católica de Chile (Chile). E-mail: pcamusg@uc.cl

3 Laboratorio de Arqueobotánica e Historia Ambiental, Instituto de Ciencias Sociales. Universidad Austral de Chile (Chile).E-mail: msolari@uach.cl 
En las últimas décadas, la crisis ambiental global ha impulsado el estudio de la historia de las relaciones de los seres humanos con la naturaleza con el objetivo de entender las raíces de los problemas que afectan actualmente a la biosfera y explicar los cambios por los cuales han atravesado los distintos ecosistemas planetarios (Worster, 1977; Glacken, 1996; Delort et Walter, 2001; Camus, 2006). Donald Worster, uno de los pioneros de la denominada historia ambiental, señala que la finalidad principal de este campo de investigación es comprender cómo los humanos han sido afectados por la naturaleza y cómo, a su vez, estos han impactado el ambiente natural y con qué resultados (Worster, 1989: 290-291).

En este contexto, el objetivo del presente artículo es comprender, en el tiempo, las interacciones entre los bosques australes y la ocupación humana del territorio de la cuenca del río Valdivia. Tradicionalmente, la visión que se tiene es que la región siempre estuvo completamente cubierta de densos bosques vírgenes de mar a cordillera y que solo a partir de la colonización de mediados del siglo XIX se habría desbrozado por medio del fuego estos territorios con la finalidad de obtener tierras donde practicar la agricultura europea, provocando con ello una transformación del paisaje sin precedentes.

Sin embargo, la investigación realizada nos demuestra, más bien, que a la llegada de los españoles había numerosas áreas despejadas de bosques y una abundante población indígena en la zona estudiada, lo cual permitió a Pedro de Valdivia fundar la ciudad que lleva su nombre y explotar los lavaderos de oro allí existentes. En este sentido, la prodigiosa selva valdiviana que avistaron los viajeros del siglo XIX no tendría más de dos siglos de existencia, y se habría formado a partir del abandono de la región por parte de los españoles luego del desastre de Curalaba y del descenso demográfico indígena provocado por las enfermedades que traían consigo los conquistadores por cambios en las estrategias adaptativas que significaron por parte de las poblaciones indígenas la explotación de la ganadería europea, por los duros trabajos a los que fueron sometidos para extraer el oro que había en aquellos parajes, entre otras razones. Esta situación histórica habría permitido el avance de la selva austral durante los siglos XVII y XVIII.

Lo anterior nos permite afirmar, tal como lo señala Luis Otero, que los paisajes, al igual que las culturas, son dinámicos y cambiantes, puesto que lo que hoy vemos en el sur del país no ha sido siempre igual (Otero, 2006: 15). Asimismo, creemos que tampoco podemos asumir una historia lineal en la cual los bosques son destruidos sin misericordia por las poblaciones occidentales. Se trataría, más bien, de relaciones sistémicas que se transforman en el tiempo de acuerdo con los niveles de ocupación y presión que se ejerce sobre el territorio, impactando o no los ecosistemas allí presentes.

Aun así, no podemos asimilar o comparar una lógica de tierras despejadas por grupos indígenas a la explotación del "recurso bosque" y la limpieza a fuego generalizada de los períodos eurochilenos. Existe una pertenencia distinta al paisaje, mientras lo alóctono presupone una forma de ver el bosque como lo contrario de lo civilizatorio, la cosmovisión mapuche-huilliche lo puebla de significaciones asociadas a sus aguas, especies vegetales, a sus inicios como cultura.

Finalmente, pensamos que el ejemplo de la cuenca del río Valdivia nos da luces acerca de las interacciones dinámicas que se desarrollan al interior del medio ambiente entre la sociedad y la naturaleza extrahumana, más allá del obvio impacto que han tenido las sociedades industriales sobre la naturaleza.

\section{Bosques y tierras despejadas en el siglo XVI}

La primera aproximación al problema es analizar la descripción de los cronistas españoles protagonistas de la conquista. Al respecto, Gerónimo de Vivar señala que la expedición de Pedro de Valdivia cruzó el río Cautín en dirección a la cordillera donde se encontraron con un lago:

"[...] muy grande. De esta laguna procede el río de Toltén, y está una isla en medio de esta laguna muy poblada de gente, donde salieron en canoas a noso- 
tros. Aquí vio el gobernador un asiento donde poblar una villa, dieciséis leguas de la mar y XIII de la ciudad Imperial y de aquí dimos vuelta hasta la costa, y asentamos en un valle que se dice Marequina, muy poblado... Visto el gobernador tan buena comarca y sitio para poblar una ciudad, y ribera de tan buen río, y teniendo tan buen puerto, fundó una ciudad, y la tituló la ciudad de Valdivia... Esta ciudad de Valdivia está asentada en un Ilano hay al derredor de esta ciudad muy grandes montes... Es muy senegoza toda esta tierra. Desde el río Tolten es montuosa. Y estos árboles son robles y arrayanes y de los avellanos que tengo dicho. Hay gran cantidad de cañas macizas... hay buena madera para casas" (Vivar, 1979: 188-189).

Tal como se desprende del relato de $\mathrm{Vi}$ var, al sur del río Toltén debió existir un tupido y denso bosque. No obstante, el texto señala que el territorio estaba muy poblado, por lo tanto también debió haber tierras descubiertas al sur del río Toltén, por ejemplo, en Villarrica, Mariquina y Valdivia. La estrategia de asentamiento es de poblaciones ocupando los valles en sectores aledaños a cursos de agua (Bengoa, 2003).

Otro antecedente lo entrega Pedro Mariño de Lobera al señalar que luego de cruzar el Toltén "[...] descubrieron una gran Ilanada con gran población de buenas casas" (Mariño, 1861: 128). Luego indica que entraron "por una tierra muy llena de espesas arboledas, aunque no de manera que impidiese el andar a caballo sin pesadumbre, y así se pudo llevar adelante el viaje sin topar gente de guerra ni aun de paz pues de ningún genero la había" (Mariño, 1861: 129). Asimismo, Lobera escribe que cerca de la desembocadura del Toltén los españoles debieron pasar "unos cerros altos que estaban sobre la mar llenos de arboleda", para luego descubrir "una comarca, muy fértil, Ilana, y desembarazada de montaña" (Mariño, 1861: 132). También señala que en las cercanías de la ciudad de Valdivia la expedición española encontró "unas grandes llanadas, tan Ilenas de poblaciones, cuanto abundantes sementeras de maíz, frejoles, papas, quínoa, y otros granos y legumbres" (Mariño, 1861: 136).
No obstante, de Valdivia al sur las tierras boscosas ocupaban cada vez mayores extensiones. Incluso en los sectores Ilanos había bosque. Es así como las superficies de tierras despejadas Ilamaron la atención de los cronistas. Sobre esta región, Lobera planteaba que "la tierra es algo montuosa pero de grandes recreaciones; porque tiene cipreses pequeños, y otros muchos árboles deleitables; sácase de ella mucha madera estremada para edificios, y gran fuerza de tablas anchas como de cedro, de que van al Perú navíos cargados" (Mariño, 1861: 139).

Vivar afirma que solo después de caminar siete leguas al sur de la ciudad de Valdivia se encontraron con tierras "muy pobladas y sin monte, porque en las siete leguas cesa la montaña. Y esta tierra que he dicho que está sin monte, no hay árbol, si no es puesto a mano. $Y$ es tres leguas de latitud y diez y doce de longitud. Este compás que está sin monte es tierra fértil de maíz y frijoles y de papas. Luego dimos en otro río pequeño que pusimos por nombre el de las Canoas, y el otro que digo se Ilama río Hueco. Y de este río de las Canoas vuelve el monte en partes espeso y en partes claro" (Vivar, 1979: 198).

Mariño de Lobera escribe sobre una expedición de Alderete en el año 1552, quien partió desde Valdivia en dirección al sur y "lo primero que halló fueron unos llanos de ocho leguas de largo y cinco de ancho, los cuales se Ilaman de Lirquino, tierra fertilísima a maravilla, de todo lo que se puede desear para el humano sustento; y así estaba muy poblada de indios, que tenían allí todo lo necesario para sus personas que eran en grande número" (Mariño, 1861: 140).

Al regresar de su expedición, el gobernador Hurtado de Mendoza fundó en los llanos, que había atravesado en su marcha al sur, junto al río Canoas, la ciudad de Osorno:

"[...] y repartió caciques y principales de toda aquella comarca en sesenta conquistadores [...] esta ciudad está tres leguas de la de Valdivia y quince leguas del lago. Está seis leguas de la mar. Tiene muy gentil Ilano. Tiene cerca leña y 
madera para casas. Es tierra fértil, dase buen trigo y cebada y se dará todas las semillas y árboles de nuestra España que se pusieren" (Mariño, 1861: 249).

Estas descripciones nos plantean que había una mayor concentración de poblaciones y de tierras despejadas de bosques en los márgenes de los ríos y lagos, como en Toltén, Villarrica, Valdivia y Mariquina, como también en los Ilanos de Osorno. Hacia el sur de los llanos, aparentemente, la vegetación y los bosques se hacían más espesos. Respecto de Villarrica, Lobera afirma que "por todos lados estaba la tierra poblada de indios en grande abundancia". Por otra parte, señala que en Valdivia había un asentamiento "donde tenían sus viviendas los naturales en razonables casas. Entraron los nuestros por esta loma y viéronla toda tan adornada de arboleda, sembrada a mano, que parecía un paraíso" (Mariño, 1861: 411).

El esplendor e importancia alcanzado por la ciudad de Valdivia en el siglo XVI permaneció en la memoria durante los siglos posteriores. El fraile Pedro González de Agüero escribe en el siglo XVIII:

"Los terrenos de Valdivia aseguran los historiadores que son abundantes de trigo, legumbres y frutas: y sobre todo aplauden las riquezas de sus minas, con especialidad las de oro y hay quien afirma que fue tan nombrado este precioso metal que su ley no bajaba de los 23 quilates" (González de Agüero, MDCCXCl: 133-134).

Todavía, durante el siglo XIX, admirado, Vicente Pérez Rosales indicaba que:

"Valdivia mereció de los conquistadores la más constante solicitud; lo prueban los escombros de sus ciudades en las cuales se notan aún el ladrillo y la piedra canteada, el tamaño de ellas, la regularidad de su planta, los rastros de sus múltiples molinos, los socavones aún hábiles para conducir las aguas perforando las colinas la tradición de sus muchos y buenos caminos de los cuales solo se conservan algunas ramblas y tal cual vestigio al través de la espesura de los bosques y las fortalezas del Corral, obra monumental en Chile y que costó tantos millones a la península" (Pérez Rosales, 1852: 6).

\section{Conquista del territorio y fundación de ciudades}

En la elección del emplazamiento de Valdivia fue determinante el río, su navegabilidad, su proximidad al mar y la calidad de su puerto, que lo hacía un sitio privilegiado para el comercio, el apresto de expediciones y el envío de socorro a las ciudades del interior (Figuras $\mathrm{N}^{\circ} 1$ y 2 ).

Los 150 vecinos fundadores configuran una muestra de las personalidades más importantes de la conquista de Chile, entre ellos, el propio Pedro de Valdivia, además de los futuros gobernadores del reino Jerónimo de Alderete, Rodrigo de Quiroga, Francisco y Pedro de Villagra. Esto ratifica la importancia y riqueza de la zona. Gabriel Guarda señala, en este sentido, que lo más elocuente es el nombre otorgado al nuevo centro urbano. El historiador Diego de Rosales indica que, de este modo, el conquistador quedaba eternizado.

Desde esta ciudad emanó la conquista hacia los ricos territorios interiores (Villarrica y Osorno). El motivo de tanta premura por levantar ciudades que ratificasen la conquista de aquellos territorios son los hallazgos de oro realizados al sur del río Toltén. Todo este oro recibirá el nombre de Valdivia por estar en esa ciudad la marca real. Lobera, al referirse al oro de Villarrica, dice que, por estar cerca de Valdivia, se Ilama "oro de Valdivia... el mejor que se saca en todo el reino de Chile". En Lima se transaba "oro fundido y marcado de Valdivia". Las fuentes insisten en la riqueza aurífera del ámbito geográfico valdiviano. El gran yacimiento se encontraba en las fuentes del río Pichoy, a doce leguas al norte de la ciudad (Guarda, 2001).

No obstante, más que la minería y el oro, en el largo plazo, el comercio fue la actividad económica más estable del siglo XVI en la región. Gabriel Guarda ha identificado 137 mercaderes, lo cual indica un 


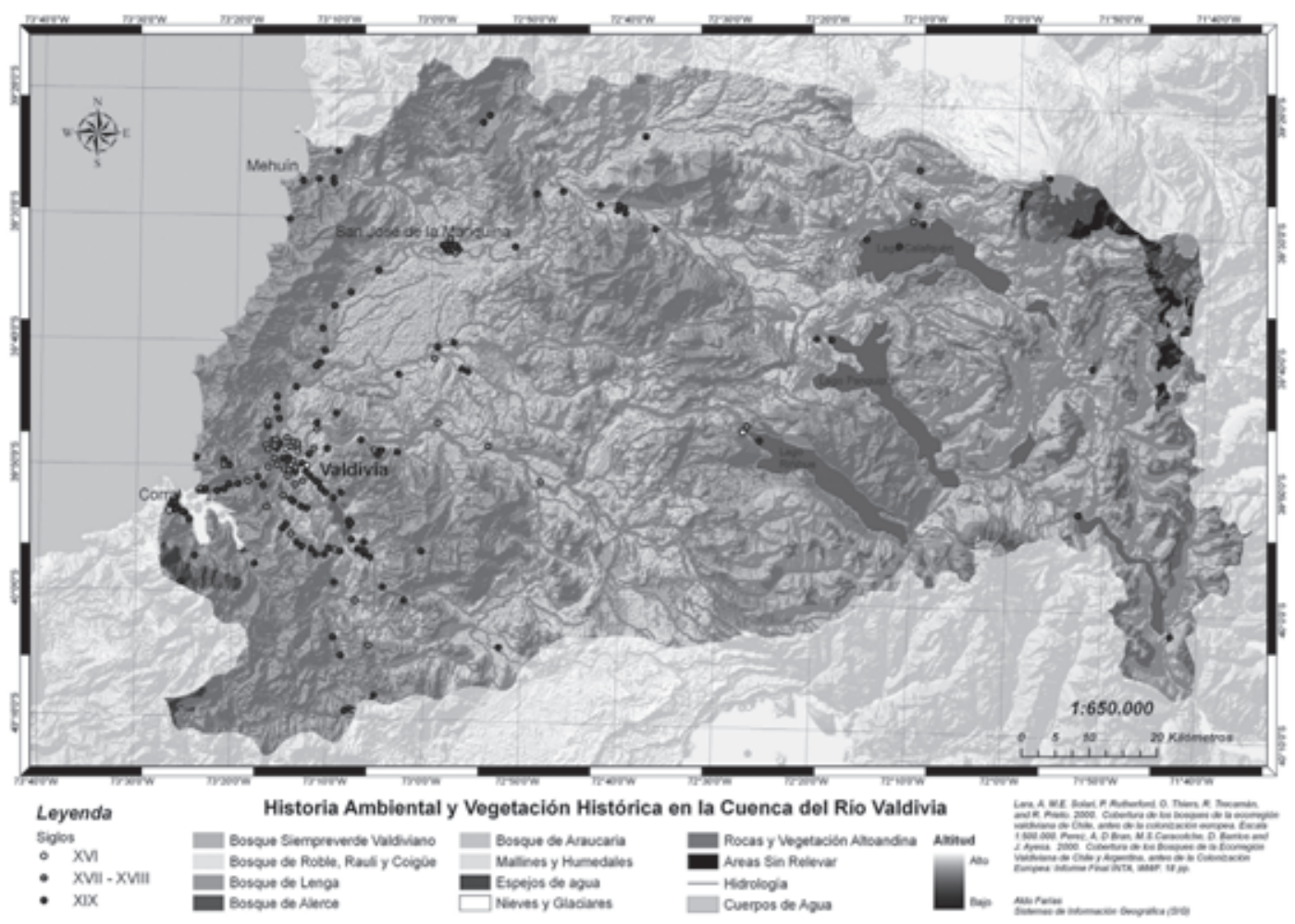

Fuente: Elaboración propia.

poco conocido, extraordinario y sorprendente movimiento comercial. Varios de los agentes comerciales de Valdivia son representantes de compañías mayores con sede en Lima. La notable actividad económica de los territorios estudiados se refleja en el desarrollo urbano alcanzado por las principales ciudades, en el comercio con Perú y en la intensa labor de los armadores de barcos, pues, en los astilleros valdivianos del siglo XVI se fabricaron las mayores embarcaciones del reino de Chile. Entre 1553 y 1603, existe un listado que identifica 79 navíos, entre los que predominan los de mayor tonelaje.

La conquista del territorio se concretará también en términos "ecológicos". Conducirá a una infinidad de transformaciones en el ambiente valdiviano. En términos generales, durante la segunda mitad del siglo $\mathrm{XVI}$, los cultivos indígenas darán paso a los cereales y el ganado hispano. La quínoa, el maíz y la papa serán reemplazados por el trigo, la cebada y los manzanos. Mariño de Lobera señala que, entre 1554 y 1555 , hubo tanta abundancia de cereal que no se recogieron 200.000 fanegas de trigo "por no haber quien las quisiese". Este testimonio nos indica la existencia de buenas condiciones climáticas en la región pues el trigo necesita el calor de la primavera y el verano. Los vacunos y los equinos también se adaptaron en forma rápida y fácil a las condiciones ambientales de Valdivia. En 1580, después de ciertas asonadas indígenas, los españoles lograron recuperar en las inmediaciones de la ciudad 10.000 cabezas, lo cual podría implicar la existencia de muchas más. Diego Rosales señala que en los Ilanos "Ios vecinos de la ciudad tenían copiosísimas sementeras de trigo, cebada, garbanzos, lentejas y otras legumbres" (Rosales, 1877-1878: 408). La Figura No3 en- 
Figura $\mathrm{N}^{\circ} 2$

OCUPACIÓN DE LA CUENCA DEL RÍO VALDIVIA POR PERÍODOS

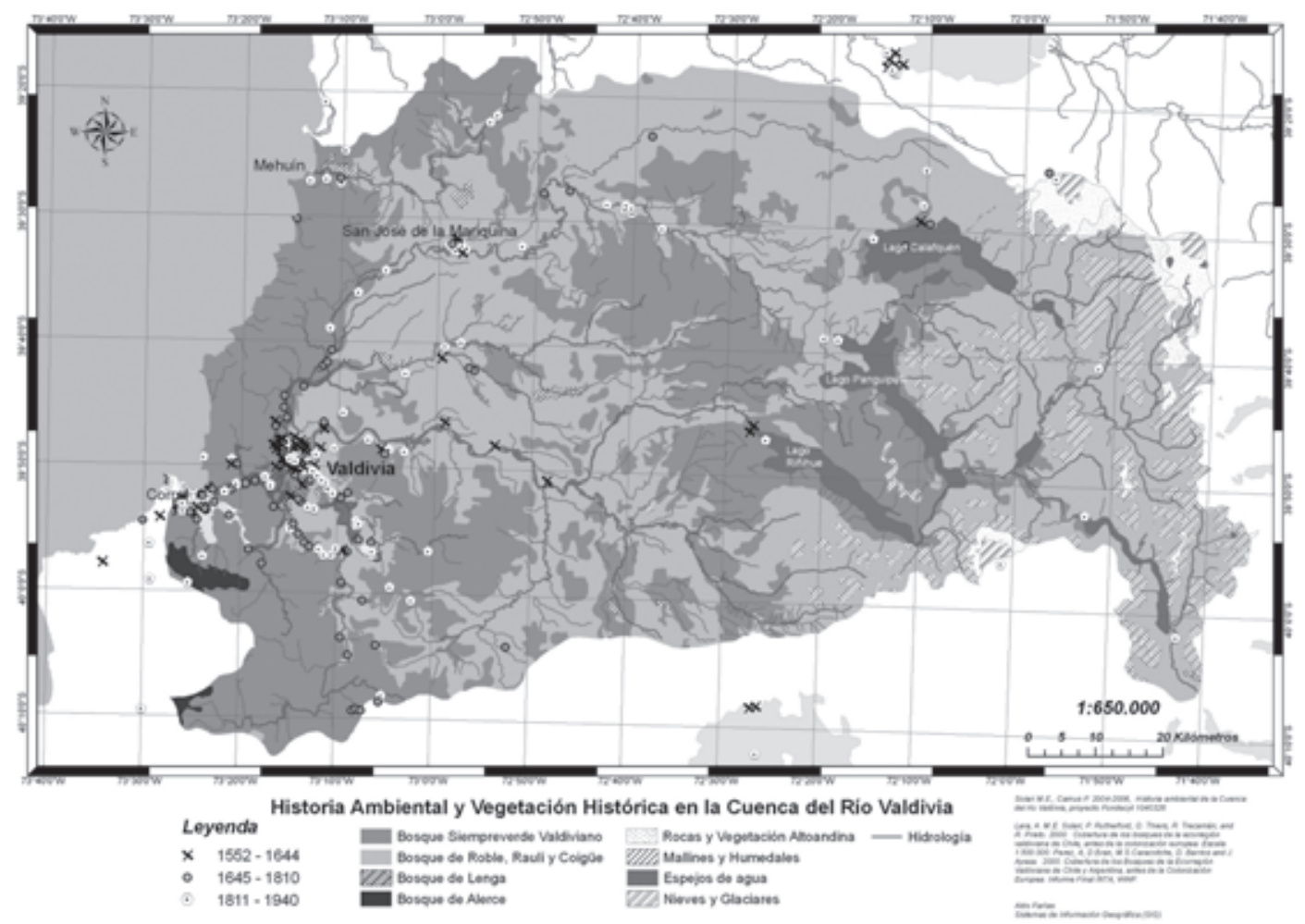

Fuente: Elaboración propia.

trega una perspectiva de la ocupación de la región, diferenciando siglos, y la Figura $\mathrm{N}^{0} 4$, por siglos y áreas.

Otro impacto de la conquista, todavía más brutal y transformador del medio ambiente valdiviano fue la mortalidad indígena. Los españoles trajeron consigo una serie de enfermedades, epidemias y pestes que diezmaron, pronto y con mayor fuerza que las armas, a la población indígena, sus costumbres y creencias. Los cronistas coinciden en señalar la mortalidad generada por la viruela y otras enfermedades desconocidas hasta entonces en aquellos territorios. En realidad, la población indígena pereció más por efecto de las enfermedades exógenas que por la superioridad de las armas de guerra hispanas. A ello habría que sumar la mortalidad causada por los trabajos forzados en los lavaderos y oro y otras actividades productivas.
El esplendor urbano de Valdivia colonial culminó a fines del siglo XVI con el levantamiento indígena iniciado en Curalaba en 1598. La ciudad desapareció por decenas de años.

El descenso demográfico indígena provocado por la conquista y la expulsión de los españoles y criollos habría permitido el avance de los bosques hacia sectores antes poblados y cultivados. De este modo, a principios del siglo XVII, la caída y el despoblamiento de las ciudades al sur del Biobío, sumado al desastre demográfico indígena provocado por la conquista, sus armas, enfermedades, pestes y trabajos forzados, permitió que los bosques avanzaran hacia los terrenos despejados, cubriendo de vegetación zonas antes intervenidas por el Hombre, especialmente aquellas ocupadas por los españoles pues para los indígenas no era oportuno ni conveniente instalarse en aquellos territorios. 


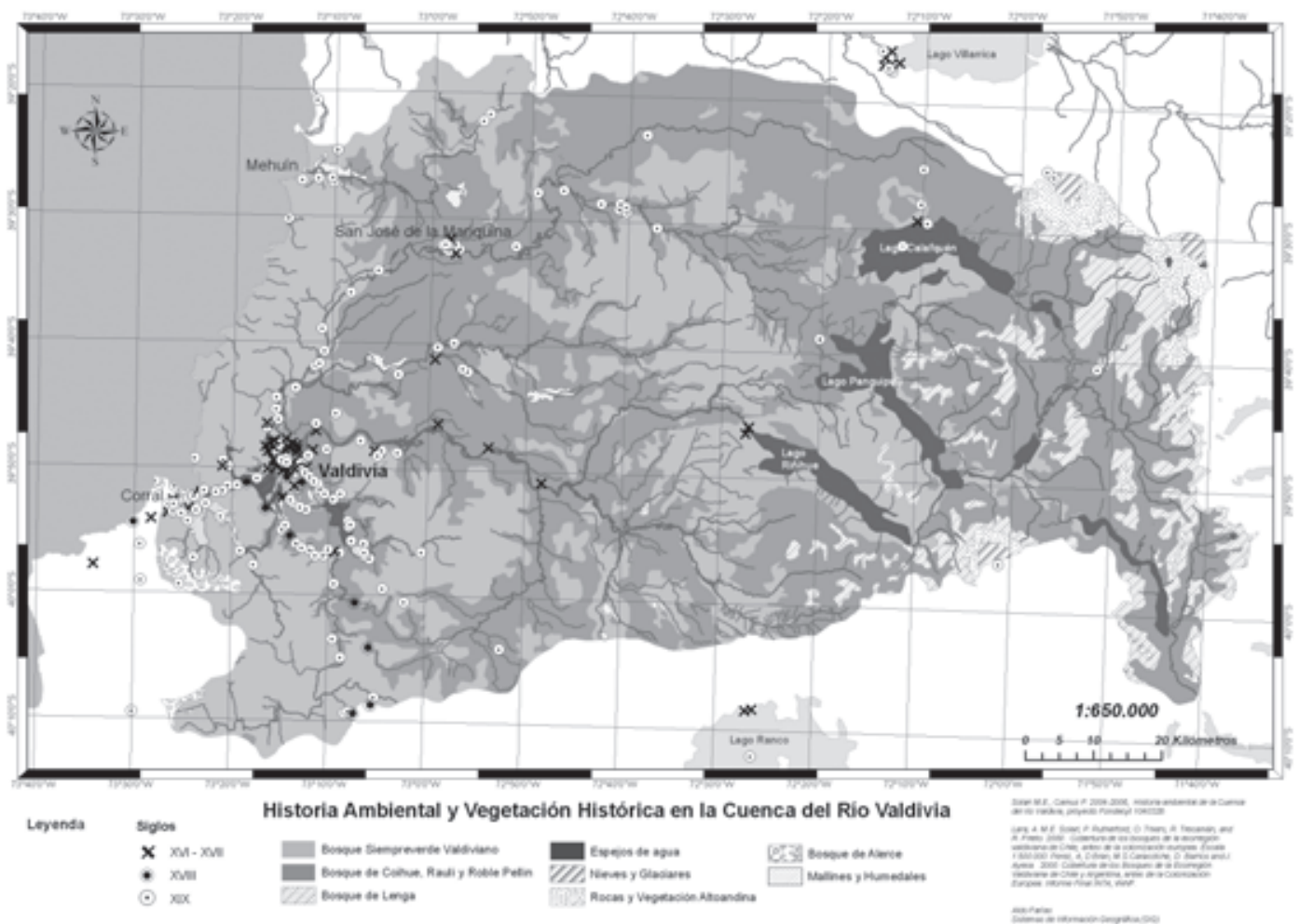

Fuente: Elaboración propia.

En este sentido, Miguel de Aguirre, miembro de la expedición que refundó la Plaza de Valdivia en 1645, señala que "ordenó el gobernador a su hijo, el capitán don Florián Gil Negrete, que con 120 hombres saliese a asegurar la campaña, reconocer los sitios, montañas y asperezas que son muchas las que de árboles y ramas han crecido a espesura de bosques, en aquel antiguo sitio que parece más que montaña áspera que humana habitación, que de la antigua han quedado muchas ruinas y paredes viejas de edificios caídos por tristes monumentos de los antiguos, y ricos solares" (Aguirre, 1647: 79).

Dos siglos después, Vicente Pérez Rosales, refiriéndose a los manzanos europeos, plantea que "ha sido tal la rapidez con que se han propagado que en medio de los bosques de los cerros y hasta en las ciénagas se le ve aparecer frondoso y cargado de su ás- pero fruto con el que se trabaja abundante sidra" (Pérez Rosales, 1852: 23).

Respecto de las parras, Pérez Rosales indica:

"[...] se me asegura aun que existen algunos parrones de extraordinaria madurez y corpulencia cuyo fruto alcanza a madurar y multitud de otros árboles frutales restos de antiguas fincas de los primeros pobladores que el trigo y las legumbres que siembran los indios con mucha imperfección se dan abundantísimos y de excelente calidad" (Pérez Rosales, 1852: 19).

Por su parte, también en 1852, Rodulfo Amando Phillipi señala, respecto del fundo San Juan de propiedad de su hermano Bernardo, que el antiguo propietario:

“[...] había obtenido del General Clarke cuarenta presidiarios y los había hecho 
Figura $\mathrm{N}^{\circ} 4$

OCUPACIÓN POR SIGLOS Y ÁREAS

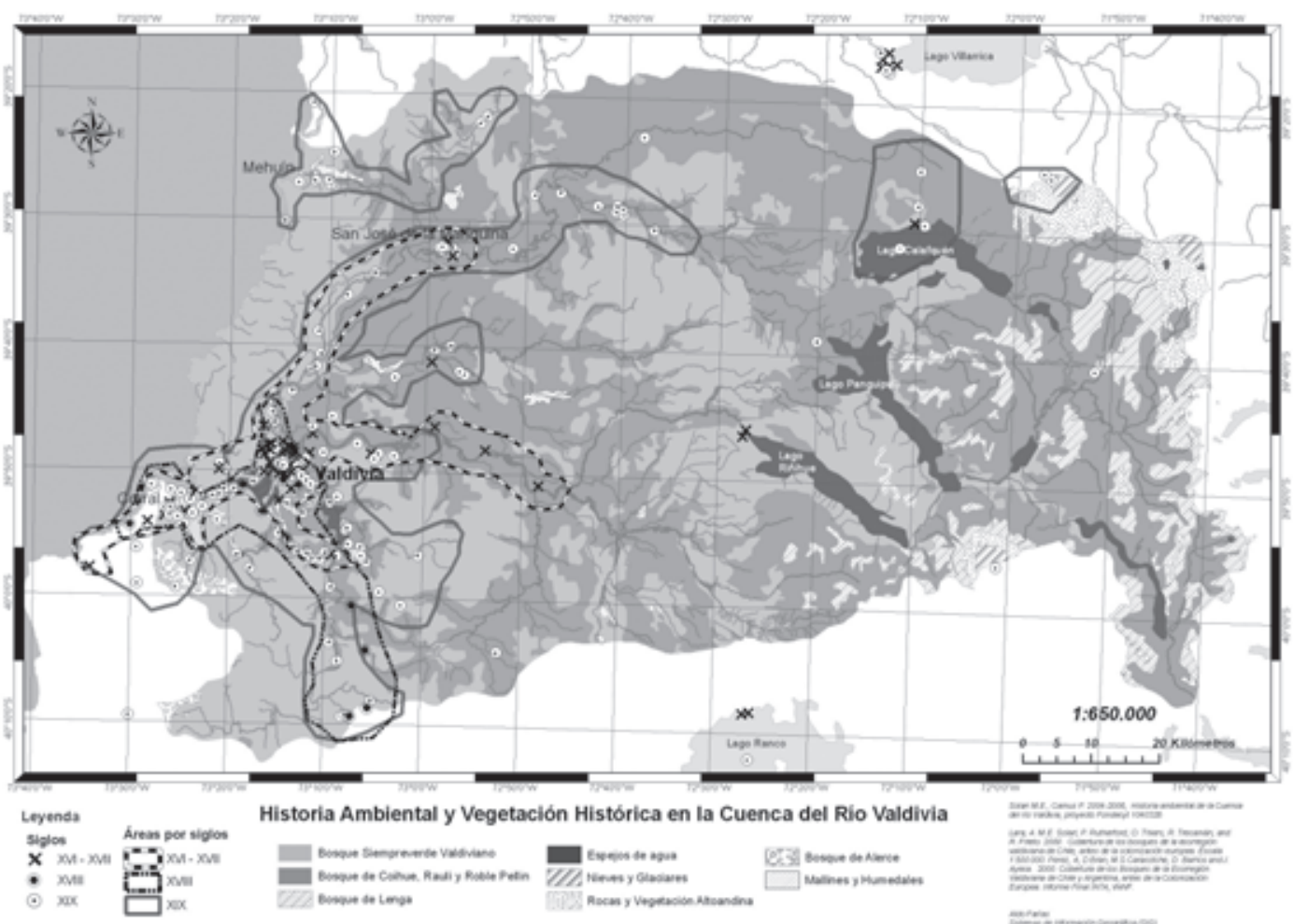

Fuente: Elaboración propia.

trabajar en dicho fundo; [...] se había desmontado una porción de terreno y se había sembrado trigo; se había plantado árboles frutales y encontrado manzanos, membrillos, ciruelos, hasta dos higueras y una parra y había más de ochenta animales vacunos, etc., en el fundo (Phillipi, 1901: 357).

La pregunta es ¿cómo llegaron esos árboles europeos ahí? Es probable que, para poder competir y adaptarse en aquellos territorios, esos manzanos fuesen plantados, inicialmente, en tierras despejadas y ocupadas por los españoles en el siglo XVI. Al respecto, a fines del siglo XVIII, Pedro de Usauro señalaba que:

“[...] por tradición sabemos que cuando los primeros pobladores en tiempos de Pedro de Valdivia fundaron esta, como poseído de indios estaba todo sin bos- ques y se experimentaba mejor temperamento y menos lluvias, dando lugar que en los cerros más elevados se encuentren las tierras labradas y paredones de caseríos y poblaciones" (Usauro Martínez, 1898: 89).

Por su parte, también en el siglo XVIII, Martínez de Bernabé también sostiene la teoría que a la llegada de los españoles "estaba todo sin bosques" (Guarda, 2001: 57). Esto contradice completamente nuestras imágenes de los territorios de Valdivia en el siglo de la conquista.

Estos testimonios indican, al menos, que lo percibido por los colonizadores del siglo XIX no sería correspondiente con la situación ambiental de la región en el siglo XVI, e incluso tampoco con los recuerdos impresos en la tradición y en los escritores de la época. 


\section{Bosques y tierras despejadas en los siglos XVII y XVIII}

La expedición valdiviana de 1777, en busca de la "Ciudad de los Césares"4, nos da cuenta de la pérdida del control español y falta de conocimiento que, por casi dos siglos, existió sobre este territorio después de la rebelión general desencadenada por el combate o desastre de Curalaba en 1598 y la consecuente caída de las ciudades del sur de Chile (Borri, 1995: 57-77).

No obstante, la expedición de 1777 no puede considerarse como un enésimo capítulo de la leyenda de los césares sino, más bien, debe comprenderse e insertarse en el contexto de la política expansiva llevada a cabo por los Borbones en la segunda mitad del siglo XVIII, que definió la colonización de nuevos territorios como un propósito de la Corona y sus agentes. En este sentido, al intento de dominar los Ilanos de Osorno, que seguían siendo los más fértiles y propicios para la agricultura de la región, se sumó la idea de explorar y reconocer otros territorios, especialmente aquellos que controlaban las rutas de acceso a los pasos cordilleranos. Aquellos territorios seguían siendo fértiles comarcas controladas por los distintos caciques indígenas. Se puede decir que la mayoría de las toponimias indígenas hacen referencia al lugar y también a la familia que gobierna y administra esos territorios o "parcialidades".

En realidad, lo que los españoles conocían de estos territorios era solamente Valdivia y sus alrededores. Todavía a mediados del siglo XVIII el interior de la región era un vasto territorio desconocido y gobernado por los "bárbaros".

Después de Curalaba, a mediados del siglo XVII, por ejemplo, Juan de Aguirre, quien estuvo en la refundación, tiene que

\footnotetext{
4 La leyenda señala que se había perpetuado por casi tres siglos una ciudad al borde de una laguna con habitantes blancos, iglesia, ritos religiosos, modos y atuendos occidentales. Se trataba de fugitivos de la devastación de Osorno, que en aquella península hallaron un lugar propicio para fortificarse, establecerse y reproducirse, además de ganados, grano y muchos piñones.
}

citar fuentes históricas para describir y explicar:

"La benignidad apacible del clima, la fertilidad copiosa y apacible de sus campos, y valles, la abundancia varia de frutos, la amenidad de su río, la salubridad de sus aguas, las arboledas hermosas de sus montes, y bosques, la comodidad de su puerto, la facilidad de sus surgideros, la preciosidad inestimable de sus riquezas en minas, metales, piedras, aguas, donde apenas hay río, apenas monte que no lave, y que no cubra granos y pepitas de oro califica a esta región como la más rica de las indias" (Aguirre, 1647: 13).

En 1645, por instrucciones impartidas por el Virrey Pedro de Toledo y Leiva, marqués de Mancera, y luego de vencer las hostilidades y escaramuzas de los huilliches, se estableció en el antiguo asiento de la ciudad de Valdivia una plaza y presidio, ya no una ciudad. Su fundación se concretó luego que, en 1643, cinco naves holandesas intentaron poblar aquellos territorios, rebelando a los caciques de la zona y ocupando la ruta que permitía el descanso y el abastecimiento de las naves que atravesaban el temido Estrecho de Magallanes (Feliú, 1926). Todo ello significaba un peligro para el imperio español. Desde Valdivia los holandeses podían iniciar la colonización del resto de América (Aguirre, 1647: 5).

Para entender la magnitud del esfuerzo por consolidar Valdivia hay que pensar que, a mediados del siglo XVI, el ejército regular del reino de Chile para toda la frontera de Arauco era de 1.500 soldados y la dotación de la plaza austral ascendía a casi a la mitad. En el virreinato peruano, los preparativos involucraron una actividad sin parangón:

"Las fábricas de murallas, fortificaciones, trincheras, y fuertes de los puertos, surgideros, y astilleros, los bajeles aprestos, y despachos de la armada, las fundiciones de artillería, armas, municiones, pólvora, pertrechos, y levas de gentes para tantas expediciones que se han visto y admirado desde el año cuarenta, no solo no se habían visto en el Perú, pero ni aun se creían posibles para después" (Aguirre, 1647: 5). 
De este modo y con mucho esfuerzo el virrey intentaba cumplir con órdenes reales impartidas hacía cuatro décadas sobre una materia considerada como de la mayor gravedad e importancia para la conservación del imperio.

No obstante, los primeros años de la Plaza de Valdivia fueron extremadamente difíciles en especial ante las vacilaciones de los gobernadores y vecinos de Santiago. Así, por ejemplo, en octubre de 1648, a tres años de la refundación, habían muerto 240 hombres y permanecían 130 enfermos, como consecuencia del consumo de la carne salada en mal estado enviada desde Valparaíso.

De este modo, la nueva etapa que se abre en 1645 deja completamente atrás la prosperidad del siglo XVI. "Centinela en medio del vasto territorio que va del Bío Bío al canal de Chacao" (Guarda, 2001: 176). Valdivia ha perdido el esplendor del siglo XVI. Hasta fines del siglo XVIII cesa el comercio, las encomiendas y la explotación de las minas; no se transita gran parte de los caminos y los bosques avanzan hacia suelos antes dedicados a la agricultura. En este contexto, surge un nuevo modelo de asentamiento hispano en América. No se trata de una ciudad, sino de una Plaza Real. Dispone de fortificaciones y de un situado enviado desde Lima. En este sentido, desde el punto de vista del imperio español, Valdivia pasa de ser una zona próspera a ser "la más costosa de las indias" (Aguirre, 1647: 3). Desde 1645 a 1820, la dependencia del virreinato se mantuvo prácticamente inalterada. En este período, que cubre casi dos siglos, Chile completo ofrecía a los adversarios del Imperio español que atravesaban el Cabo de Hornos una multitud de puertos y lugares de descanso y aprovisionamiento. Cualquier intento contra el virreinato exigía la ocupación de Chile, que era la "Llave del Pacífico". En este contexto, Valdivia era considerado como "el antemural por excelencia". Gabriel Guarda ha identificado trece proyectos de ocupación extranjera y no excluye la probable existencia de otros (Guarda, 2001: 179).

\section{Bosques y tierras despejadas en el siglo XIX}

En 1835, en su excursión por el territorio valdiviano, Charles Darwin observó "solo espesa selva", hasta que, por la tarde, al Ilegar a la cima de una colina divisó el "admirable panorama de los Ilanos. La vista de esas inmensas llanuras sirve de verdadero alivio cuando, desde tanto tiempo, se ha permanecido sepultado, por así decirlo, en una selva perpetua, cuyo aspecto acaba por ser monótono". Los Ilanos formaban la parte "más fértil y la más poblada de este país, porque poseen la inmensa ventaja de estar enteramente desprovista de árboles" (Darwin, 1996: 189). No obstante, entre la selva y los Ilanos atravesó "algunas pequeñas praderas donde no se encuentra sino un árbol o dos, como en los parques ingleses; a menudo he observado con sorpresa que, en los distritos boscosos y ondulados, los árboles no crecen en las partes Ilanas... Cudico es un distrito intermedio entre la selva y los llanos. Se ve un gran número de cottages con campos de trigo y de patatas que pertenecen casi todos a indios" (Darwin, 1951: 357 y 358 ).

Poco después, promediando el siglo XIX, al llegar a Corral por vía marítima, Paul Treutler señala que la bahía estaba "completamente rodeada por serranías abruptas, que se elevan hasta unos mil pies, cubiertas desde la cima hasta el río de selva virgen" (Treutler, 1958: 178). Remontando el río Valdivia encontró sus orillas "cubiertas a ambos lados por tan densas selvas vírgenes, que las ramas de los árboles se extendían a menudo hasta muy adentro del río. Los exuberantes quilantos y colihuales formaban una muralla impenetrable y solo se podía desembarcar en las pocas partes donde los colonos habían despejado el bosque, para formar algunos campos y establecerse" (Treutler, 1958: 282).

En realidad, las vecindades del río Valdivia y sus afluentes no tenían importancia alguna como terrenos agrícolas. Los terrenos labrados o cultivados eran muy reducidos y la producción escasa. Solo las maderas eran abundantes. Paul Treutler plantea que "gracias a las inmensas selvas que había en la 
provincia de Valdivia y que se encontraban inmediatas a la orilla del mar o junto a los ríos navegables, uno de los principales artículos de exportación eran las maderas, las cuales tenían excelente calidad, lo que favorecía su comercio" (Treutler, 1958: 291).

El propósito de las exploraciones de Treutler era encontrar las riquezas auríferas de Valdivia, pues, como hemos visto, según los mitos, las leyendas y los relatos de los cronistas, esta había sido una región donde abundaba el precioso mineral. No obstante, Vicente Pérez Rosales, agente de la colonización y conocedor de aquellos parajes, dudaba de la posibilidad de encontrar grandes yacimientos de oro en la región. Al respecto estimaba que había sido "en vano buscarlas y hasta ahora se alimenta el minero aquí con tradiciones. Oro hay en todas partes sin embargo pero en tan ruin cantidad que no paga el trabajo de la extracción. El verdadero origen de la ponderada riqueza de Valdivia en este metal precioso, solo lo encuentro en las leyes que regían a las regiones recién conquistadas por los españoles en América. El sistema de encomiendas de indios daba a cada encomendero multitud de brazos a los cuales se les imponía la obligación forzosa de entregar a sus amos cada día una cantidad determinada de polvo de oro. Hubo hombre de estos que tuvo aquí según afirman hasta 5.000 indios de encomienda; por poco pues que cada individuo recogiese debía producir al patrón una monstruosa entrada. De aquí la fama del mucho oro que se exportaba desde Valdivia y el motivo por el que en varios puntos de la provincia se encuentran aun colinas enteras trastornadas, terrenos hollados, y rastros de acequias que aparecen sin objeto entre los bosques (Pérez Rosales, 1852: 26).

Otro dato interesante que aporta Vicente Pérez Rosales es que, a pesar de los bosques, la región "no carece de ninguna de las razas de animales domésticos que posee el norte. No abunda como antes en ellas que llegaron a ser un objeto de lucrativa especulación sobre Concepción; pero bastan a su escasa población y al abasto de la vecina provincia de Chiloé. El ganado mayor de asta se considera como el más sobresaliente de Chile [...] el trigo blanco, la cebada y el maíz introducido por los españoles; la ave- na y el centeno por los alemanes se cultivan con buen éxito en el interior y la papa parece natural de estas regiones en todas partes" (Pérez Rosales, 1852: 27).

Asimismo, nos señala que había cultivos de frutos europeos especialmente de manzanos. Todo esto nos indica que a mediados del siglo XIX la región estaba poblada y pese al avance de los bosques había numerosos espacios despejados y propicios para los cultivos agrícolas. Rodulfo Phillipi, al narrar las peripecias que vivió para definir los límites de la propiedad de su hermano, nos da cuenta que, a pesar del posible avance de los bosques y de las tupidas selvas, había un profundo conocimiento de aquellos territorios y sus deslindes. Al respecto señala que:

"Ramón Soto, cuyo terreno colindaba con el mío del lado poniente, pretendía una porción de terreno en que estaba el rancho de su vaquero; los otros vecinos eran de parecer contrario; para zanjar esta dificultad se llamó a un viejo indio, llamado Bernardo que vino con dos indios más y rechazó la pretensión de Soto, que tuvo que conformarse con su sentencia" (Phillipi, 1852: 358).

Ignacio Domeyko en su "Memoria sobre la colonización de Chile" señala que "la colonización de los terrenos baldíos mediante una inmigración europea, es una de las cuestiones vitales para Chile". Sin embargo, más adelante nos indica que "a cualquier punto, pues, que se dirija el colono, cualquiera que sea el lugar donde se trate de establecer una colonia, hemos de topar necesariamente con propiedades ya ocupadas, con habitantes pertenecientes en cuerpo y alma a la familia chilena: por todo el territorio hallará el inmigrado sino caminos, a lo menos senderos trajinados desde la conquista y trechos de suelo desmontado" (Domeyko, 1850: 4).

Reafirmando lo anterior plantea la necesidad de una mensura exacta de los terrenos fiscales y "un cierto desengaño que el gobierno debe haber sufrido respecto de la extensión y el lugar de los terrenos baldíos que creía ser de propiedad fiscal. Una ligera averiguación del asunto ha hecho ver que, tanto los terrenos ubicados al interior del 
departamento de Osorno, especialmente al noroeste de la laguna de Llanquihue, como los de las márgenes del río Bueno, del río Cruces, etc., tienen en gran parte dueños, y es de toda necesidad deslindar la propiedad del Estado con la de los particulares" (Domeyko, 1850: 8).

De hecho plantea que "el objeto de la colonización en Chile no es poblar los terrenos incultos sino introducir buenos hábitos y costumbres" (Domeyko, 1850: 10). Esto nos indica, al menos, que, a pesar de un posible avance de los bosques hacia tierras antes despejadas, el territorio era perfectamente conocido, delimitado y apropiado. Por ello, para el Estado y sus agentes el levantamiento de un plano lo más exacto posible de las provincias de Valdivia y Chiloé era indispensable no solo para conocer aquellos territorios sino también para su buen gobierno y administración. Se trataba de un conocimiento básico e indispensable para la colonización y "tan esencial que, mientras no se efectúe, ninguna medida general y extensa podría tomarse para activar y atraer la emigración europea a Chile" (Domeyko, 1850: 9).

En todo caso hay que tener en cuenta las apreciaciones del agente de Colonización Vicente Pérez Rosales quien, en 1870, planteaba:

"Con la convicción en que aun estamos, de que el Estado posee en el sur inmensos y feraces campos, parece increíble que las primeras dificultades que se opusiesen a la mencionada colonia, tanto en Alemania como en el mismo Chile, naciesen de la carencia casi absoluta de tales terrenos fiscales en la República. El mismo abandono en que yacían los estaba entregando desde tiempo inmemorial a la rapacidad de los poquísimos pobladores que ocupaban las despejadas orillas de un río, o las playas del mar sin poder penetrar más adelante se consideraran dueños de lo que hasta ahora Ilaman CENTROS ... ese fue el motivo que dio origen a que se fundase en el lejano y casi desconocido territorio de Llanquihue la modesta colonia, cuya cabecera política, Puerto Montt, lo es hoy de una provincia entera" (Pérez Rosales, 1870: 3).
Al respecto, citando un documento de la intendencia de Valdivia atribuido a Pérez Rosales, los autores de "Historia de la constitución de la propiedad austral", Donoso y Velasco transcriben:

“Cuando algún vecino quería hacerse de propietario exclusivo de algunos de los terrenos usufructuados en común, escribe en su ameno libro, no tenían más que hacer que buscar al cacique más inmediato. Embriagarle o hacer que su agente se embriague junto al indio, poner a disposición de éste y de los suyos aguardiente baratito y tal cual peso fuerte, y con solo esto ya podía acudir a un actuario público, con vendedor, con testigos o con informaciones juradas que acreditaban que lo que vendían era legitima propiedad del vendedor. Ninguno objetaba este modo de adquirir propiedades, cuyo valor se repartían amigables, el supuesto dueño que vendía y los venales testigos que lo acompañaban por ello de hoy por ti y mañana por mí. La única dificultad que ofrecía siempre esta frágil y corriente maniobra era la designación de los límites del terreno que la venta adjudicaba por que no era posible hacerlo en medio de bosques donde muchas veces ni las aves encontraban suelo donde posarse" (Donoso y Velasco, 1928: 109-110).

Según Francisco Vidal Gormaz, los afluentes del río Valdivia, es decir los ríos Angachilla, Cantera, Tornagaleones, Naguilan, Cutipai, tenían las riberas boscosas, cubiertas de exuberante vegetación, notándose, no obstante, de trecho en trecho "algunas chozas, cuyos habitantes cultivan pequeños retazos de tierra i labran madera de varias clases (Vidal Gormaz, 1863: 274). La misma impresión nos deja Rodulfo Philippi quien señala que remontando el río Futa:

"[...] apareció otra pampa a orillas del río mucho más grande y ancha, con algunos ranchos al pie de las colinas, habitaciones de los hogadores e inquilinos del señor Jaramillo, quien tenía una tenía una casa bastante decente, al extremo de la pampa y situada como a ocho o diez metros sobre el río" (Phillipi, 1852: 830). 
Estos asentamientos, sumado a los litigios por deslindes citados más arriba, nos indican un territorio poblado en muchos sectores. Debemos fijarnos también que si bien los viajeros describen bosques impenetrables, generalmente, a la vuelta de la loma, observan sectores más Ilanos, cultivados y habitados, aunque sea por "miserables chozas".

En su expedición hacia la Araucanía, Paul Treutler navegó aguas arriba por el río Cruces. Su orilla occidental se encontraba al pie de la cordillera de la Costa y se hallaba densamente poblada de bosques. No obstante, la montaña formaba, "a trechos, barrancos junto al río, o bien daban margen para la formación de terrenos planos, en el que hay habitaciones y tierras bien cultivadas, que se extienden hasta cerca de San José. La orilla oriental, en cambio, es completamente llana, con solo unas escasas colinas bajas, y se hallaba cubierta por selva virgen impenetrable, en la que solo se habían descampado algunos paños de terreno para cultivarlos" (Treutler, 1958: 301).

Más adelante, en un lugar denominado Tres Bocas, en la casa del señor Exss, un alemán comerciante de maderas, que estaba situada a unos sesenta pies sobre el nivel del río, Treutler observó que, en general, lo que predominaba en la región era el bosque:

"Hasta donde alcanzaba mi vista, se extendía la selva virgen e impenetrable. Hacia el oeste llegaba hasta la cima de la cordillera de la Costa y, de norte a sur, cubría un valle de unas 20 leguas de largo, que limitaba al este la cordillera de los Andes. En ésta se erguía el volcán ViIlarrica, cuya cima cubierta de nieve y coronada de humo y fuego dominaba la verde masa de árboles. La espantosa uniformidad de la región solo era alterada un poco por los grandes ríos que se unían en esa parte, los cuales serpenteaban en forma de anchas fajas plateadas a través de la inmensa selva virgen, describiendo meandros" (Treutler, 1958: 303-304).

Más al norte, en un sector denominado Chunimpa, el río dejaba de ser navegable. Se trataba del "primer lugar desde Valdivia, donde el suelo fértil permitía arrebatar ma- yores superficies a la selva virgen, a fin de destinarlas a la agricultura; pero también aquí solo se encontraban algunas miserables chozas" (Treutler, 1958: 304).

Luego, siguiendo por la orilla del río, Treutler llegó a San José. Desde allí el terreno se presentaba cada vez más fértil y observó que iba en aumento la tierra cultivada. Pasó frente a los caseríos de Paico, Esperanza, Cuncún, Calfuco, Huillín, La Chacra, Asque, Calchatué y Tapia, que comprendían solo algunas chozas. Después de tres horas de cabalgata arribó a la misión de San José, a siete leguas de Valdivia. Desde allí se dirigió hacia el poniente por un sendero plano y bien trazado a través del bosque, en dirección hacia la cordillera de la Costa. Después de dos horas llegó a un estrecho valle denominado Tres Cruces, donde se encontraban algunas chozas y campos cultivados y luego prosiguió por un camino "tan estrecho, que lo podía usar solo un caballo, pues a ambos lados se elevaba la selva virgen, impenetrable, cual muralla. Luego la vegetación era tan exuberante, que si nadie transitaba el sendero durante algunos días, se juntaban de tal manera una infinidad de enredaderas y plantas parásitas que, para pasar, era preciso despejar con el machete la red que formaban" (Treutler, 1958: 315).

Luego de avanzar cuatro horas por este camino, Treutler llegó a un valle, cruzó el río Lingue y después de media hora de viaje, llegó a una llanura con campos cultivados, bosques de manzanos y algunas viviendas: era el caserío de Mehuín. Luego, cruzando el estero Queule, después de una cabalgata por la arena, se encontró con el cerro Nihue, el cual debió escalar y no rodear, pues avanzaba mucho hacia el océano y estaba tan poblado de bosques como el resto de los cerros. Finalmente al arribar al Toltén, observó que un caserío habitado por unas 200 familias se extendía casi media legua a lo largo del río. El terreno "era plano y extraordinariamente fértil. Crecían muy bien el trigo, las habas y el maíz, y llamaba sobre todo la atención una papa alargada, conocida en todo Chile como papa tolteña. Magníficas praderas, pobladas por grandes rebaños de caballos, vacunos y ovejunos, se extendían hasta el pie de la cordillera andina" (Treutler, 1958: 330). 
Es decir durante el viaje mismo, y más allá de la mirada general, Treultler describe una buena cantidad de tierras despejadas y ocupadas por "miserables chozas", según su recurrente expresión.

En su segunda expedición hacia la Araucanía, Treutler avanzó desde San José de la Mariquina, hacia el noreste, con dirección a la cordillera andina. Después de una hora de avanzar por terrenos boscosos y por pastizales pasó por los caseríos indígenas de Chonqui y Quechupulli, para llegar, luego, al de Marilef. Después cabalgó entre cerros cubiertos de espeso bosque virgen, hasta llegar a un altiplano donde había una choza, grandes manzanos y campos cultivados. Desde ahí realizó un largo recorrido remontando el río Cruces y el Leufucahue, donde encontró varios caseríos indígenas y algunos trechos de selva. Finalmente, Treutler arribó al lago Trailafquén, denominado ahora, Calafquén. Al dirigirse a Villarrica atravesó algunos espacios cubiertos por densa selva, pero, por diversas circunstancias, no logró llegar a las ruinas de Villarrica, como era su objetivo. Le habían dicho que a pesar que "un denso bosque cubría el lugar de la antigua ciudad y sus fortificaciones, restos de construcciones en pie le permitirían reconocer las calles y plazas, y los grandes edificios, como iglesias y monasterios" (Treutler, 1958: 373).

En su tercera expedición a la Araucanía, Treutler se dirigió por el río Cruces a San José, y de ahí hacia el norte, hacia Pitrufquén. El camino, que era malo hasta $\mathrm{Ni}$ guén, se convertía en intransitable más al norte. Durante seis horas avanzó en medio del denso bosque hasta que llegó a PichiMaquehua y luego a Quesquechán, que resultaron ser para su percepción dos agrupaciones de rucas abandonadas, derruidas y rodeadas por manzanos. Luego prosiguió el viaje por el bosque y avanzó "por el camino más malo que jamás haya andado en toda mi vida". Pasaba por una selva espesísima. El sendero tenía el ancho solo necesario para que pasara apenas un caballo. Había, además, troncos de cinco a seis pies de diámetro que estaban atravesados por el camino y que junto a las filudas quilas y las enredaderas dificultaban extremadamente la marcha. Empleó tres horas en avanzar solo tres leguas, a lo largo de las cuales saltó más de cien troncos de todos los tamaños. Finalmente salió del bosque y llegó a Quitratúe donde fue acogido por el cacique Lemunao. Al día siguiente después de avanzar una hora llegó al caserío de Cupe y luego de cinco horas cabalgando por un bosque vio una gran planicie, al fondo de la cual se levantaba junto al río Toltén el caserío de Pitrufquen, una de las aldeas más importantes de la Araucanía que contaba con unas cuatrocientas almas. El Toltén era atravesado desde el mar hasta los Andes por terrenos agrícolas fértiles. No obstante podía advertir muy bien como la "población había disminuido, pues grandes trechos, antaño cultivados, se encontraban ahora yermos o estaban cubiertos en gran parte por arbustos, y hasta por árboles en los lugares abandonados por más tiempo" (Treutler, 1958: 388).

En suma, de acuerdo con las descripciones realizadas por Treutler, podemos señalar que inmediatamente al sur del río Toltén comenzaba un espeso bosque. Solo se encontraban algunos claros de diversas extensiones que en parte estaban poblados. La comunicación entre ellos se hacía por senderos difícilmente transitables en medio de la selva valdiviana. Solo en el sector del curso medio del río Cruces había una mayor extensión de tierras despejadas: se trataba de la Mariquina. Aguas arriba las chozas indígenas en medio de grandes manzanos y con sus campos de cultivo y pastizales, alternaban con los sectores boscosos.

De Valdivia al oriente, hacia la cordillera de los Andes, el lago Ranco estaba "rodeado en su mayor parte de selva virgen" (Treutler, 1958: 433). No obstante, en dirección al lago existían poblados indígenas y planicies de pastos separados entre sí por la selva. En general, la superficie despejada seguía el curso de los ríos valle arriba y de las pampas que se formaban, donde se encontraban los grupos indígenas. Entre los Ilanos y los lagos cordilleranos, debió dominar un espeso y cerrado bosque pues este sector permaneció inexplorado por largo tiempo.

En términos generales, un observador tan respetado como Phillipi escribe:

“[...] la vegetación de esta provincia era tan vigorosa i lozana, que una pampa 
abandonada a sí misma, en pocos años se vuelve monte. Es lo que palpo todos los años en mi fundo. Muchos lugares que eran campos i cultivos al principio de este siglo, ahora están cubiertos de árboles grandes e impenetrables por la quila i otros arbustos; se conocen distintamente caminos distintos en el monte ahora enteramente cerrados e intransitables, i aun en los ocho años que poseo este fundo varias pequeñas pampitas se han cubierto de monte nuevo" (Phillipi, 1860: 625).

En este sentido, Phillipi planteaba: "debo tocar un hecho que ha llamado mucho mi atención i que merece tal vez fijar la atención del gobierno, i es que el monte invade más i más la provincia de Valdivia. No puede caber la menor duda que esta parte de la República era sumamente poblada cuando los españoles la descubrieron. D. Pedro de Valdivia i sus sucesores encontraron ejércitos numerosos, i había miles de indios sitiando al mismo tiempo las ciudades de Valdivia i Osorno. Estos se alimentaban entonces únicamente de vegetales, pues no conocían ningún animal doméstico, i las vacas, ovejas, caballos no habían tenido tiempo de multiplicarse i de llegar a ser un alimento de los más pobres. Esta circunstancia sola es una prueba evidente de que debían cultivar una extensión mucho mayor del que se cultiva en el día" (Phillipi, 1860: 624-625).

Sobre el posible avance de los bosques, podemos encontrar testimonios notables como el de Francisco Vidal Gormaz, escrito en 1869:

"Al recorrer nosotros el territorio litoral i parte del interior, comprendido entre el río Imperial y el archipiélago de Chiloé por el espacio de cuatro años consecutivos, hemos podido notar el incremento rápido de los bosques. Por todas partes, se notan vestigios de rucas e inmensos retoñales al paso que los desmontes modernos o más propiamente contemporáneos, son mucho más reducidos i limitados, fenómeno que hacer ver la disminución de la población indígena i con ello el incremento de los bosques" (Vidal Gormaz, 1870).
En su cuarta expedición, esta vez hacia el territorio huilliche, Paul Treutler, remontó el río Futa, al sur del río Valdivia, en dirección a las colonias agrícolas fundadas por los alemanes en el interior. Después de ocho horas de navegación Ilegaron a Futa, un villorrio de una docena de casas, situadas en una llanura descampada y rodeada de altos cerros cubiertos de bosque virgen, que era el punto hasta donde se podía navegar el río. Desde allí el camino subía y bajaba entre la selva por siete horas hasta que comenzó a despejarse y a ambos lados del camino aparecieron campos cultivados, viviendas dispersas y praderas. Al Ilegar a La Centinela, antiguo puesto militar español, Treutler observó hacia el sur "la inmensa planicie que alcanza desde el pie de la serranía hasta el golfo de Reloncaví. En primer plano había un gran número de chozas a la sombra de grandes manzanos y en medio de campos cultivados y praderas, donde pastaban numerosos rebaños. Una legua más allá se encontraban las casas dispersas del pequeño pueblo de La Unión y más allá en el borde de la selva, se elevaban las torres de la antigua ciudad de Osorno. Hacia el oeste la planicie estaba limitada por la cordillera de la Costa, que tenía una altitud de más de 1.000 pies, y al este por el molo gigantesco de la cordillera de los Andes" (Treutler, 1958: 441).

De Osorno al sur había un camino abierto en la selva, que en diez horas de viaje llevaba a la orilla septentrional del lago Llanquihue. Este camino era tan pantanoso -excepto en un trecho de tres leguas donde un gigantesco incendio había destruido la selva- que había sido "necesario colocar planchadas a lo largo de muchas leguas a fin de que no se hundieran los jinetes con sus bestias".

Al parecer, los llanos de Osorno y La Unión, con sus casas diseminadas rodeadas de manzanos, sus trigales, sus dehesas con pasto y árboles intercalados, eran una verdadera isla de tierras despejadas en medio del mar de árboles que rodeaban sus cuatro costados.

Vicente Pérez Rosales describió esta planicie de la siguiente manera: "El valle central encajonado por dos grandes selvas que 
constituyen una masa compacta de la más poderosa vegetación es una bella llanura casi enteramente desprovista de grandes árboles i apta para toda clase de cultivos de los países templados" (Pérez Rosales, 1859: 304).

En coherencia con las teorías sobre la influencia de los bosques sobre el clima y dando cuenta de la magnitud de los bosques que observaba, Vidal Gormaz pensaba en sus conclusiones que en esta zona no era "la latitud la dificultad mayor que se opone al desarrollo de la agricultura en la región comprendida al sur del río Imperial i que podemos extenderla hasta el archipiélago de Chiloé: son los inmensos bosques que tapizando el terreno temperan el clima estival sin permitirle alcanzar el calor suficiente para que maduren los granos a tiempo oportuno i las frutas alcancen su desarrollo y sazón" (Pérez Rosales, 1859: 333).

No obstante, en 1859, el Ministro de CoIonización Vicente Pérez Rosales, expresaba que de hecho la región seguía enteramente cubierta de extensas selvas, excepto en aquellos sectores donde se hacía sentir la acción de los colonizadores, en especial en el valle central. La forma más recurrida para limpiar el bosque era el fuego: "así, los colonos que se han establecido allí no han necesitado más que prender fuego a las malezas y a las plantas sarmentosas y trepadores que entrelazan los árboles, para procurarse hermosos campos de una fertilidad poco común para los trabajos de agricultura" (Pérez Rosales, 1859).

Refiriéndose a la zona de Osorno, GuiIlermo Doll advertía en 1858 que "casi toda la región, que antes presentaba un bosque impenetrable, ha quedado accesible y presentada al cultivo por el gran incendio de monte ocurrido en el verano de 1851. Este fue tan violento en muchas partes que solo han permanecido en pie los restos de los troncos más viejos". Asimismo, es conocido el relato de Pérez Rosales, en su obra Recuerdos del Pasado, sobre la acción del indio incendiario Pichi Juan en las selvas de Chan Chan, entre La Unión y Osorno.

Se trata de las primeras evidencias de la colonización de aquellas tierras cubiertas por bosques pero esperando ser despejadas mediante el fuego del agricultor y el ganadero, interesados en quemar los bosques para obtener espacio donde realizar sus actividades productivas. El bosque era visto, más bien, como un enemigo al que había que eliminar con el objetivo de hacer florecer el progreso en estos territorios.

Las dificultades del transporte, dadas por la existencia de caminos precarios, muchos de ellos transitables solo en verano, originaron una explotación de los recursos naturales que fue creciendo en forma paulatina, a medida que se mejoraron las rutas de comunicación. De este modo, a fines del siglo XIX, el paisaje natural de la región ya presentaba ciertas transformaciones como resultado de la ocupación y explotación de los colonos alemanes y chilenos del territorio (Bernedo, 1999).

La construcción del ferrocarril longitudinal sur hasta Osorno y Puerto Montt fue un factor de modificación del medio natural más intenso puesto que permitió que los productores regionales incrementaran sus relaciones comerciales con el resto del país. Las fuerzas económicas y productivas se vieron fuertemente estimuladas por la baja en los fletes y del tiempo de traslado de sus productos. Como respuesta se explotó más la madera, se extendieron las áreas destinadas a la crianza de ganado vacuno y se ampliaron los cultivos de trigo, cebada y papas. El creciente desarrollo de estas actividades productivas implicó despejar muchas veces con fuego grandes extensiones de bosque nativo (Camus, 1997).

\section{Consideraciones finales}

El estudio realizado nos permite comprender la dinámica histórica de los bosques de la región valdiviana más allá de los prejuicios tradicionales que sindican al hombre occidental como el destructor de un paisaje prístino e intocado por la mano humana, reivindicando de ese modo el "mito del buen salvaje" y, de paso, desconociendo la presencia y los avances culturales de las sociedades indígenas. A partir de los testimonios e ideas expuestas, no es aventurado plantear que en el siglo XVI había menos bosques en la cuenca del río Valdivia que 
en el siglo XIX. La numerosa población que habitaba esta región permitió a los españoles explotar los lavaderos de oro y fundar tres ciudades que tuvieron una importante gravitación urbana en el siglo XVI. Asimismo, otro elemento que nos permite afirmar la existencia de tierras despejadas y ocupadas es la introducción de cultivos europeos como el trigo que requiere de un cierto grado de calor para madurar y de árboles como los manzanos que debieron ser plantados en espacios despejados de bosque, pues, de otro modo, difícilmente ambas especies podrían haber prosperado en medio de la húmeda selva valdiviana.

Las fuentes consultadas nos indican que con la desaparición de las ciudades al sur del Biobío, después del desastre de Curalaba y el descenso demográfico indígena provocado por el impacto de la conquista, unido a un cambio en la estrategia de habitar el territorio por los grupos mapuche-huilliche, que significó un énfasis mayor en una actividad móvil y extensiva como es la ganadería, los bosques avanzaron en la región de Valdivia ocupando en los siglos XVII y XVIII buena parte de las tierras que estaban despejadas en el siglo XVI. Lo anterior no implica que estos territorios no pertenecieran a las diferentes parcialidades indígenas y que formaran parte de sus paisajes e imaginarios patrimoniales, como lo prueban los numerosos pleitos de tierras que se dieron durante el siglo XIX, entre colonos eurochilenos $y$ habitantes indígenas.

Si bien exploradores y colonos del siglo XIX insisten en describir la región como prácticamente cubierta por bosques y con un escaso grado de antropización, las fuentes también señalan la existencia de claros y de restos culturales indígenas en el bosque, lo cual nos plantea la persistencia de asentamientos humanos en la primera mitad del siglo XIX aunque pensamos que en un grado bastante menor que en el siglo XVI. Es la imagen legada por los viajeros del siglo XIX la que nos induce a imaginar una región cubierta de bosques en el siglo XVI, aun cuando a través de esta investigación creemos haber demostrado que se trata de una falsa imagen pues buena parte del territorio sobre todo cerca de los ríos y lagos se encontraba despejado de bosques y utilizado por sus habitantes.

\section{Referencias bibliográficas}

AGUIRRE, M. Población de Baldivia: motivos y medios para aquella fundación. Defensas de Reyno del Perú, para resistir las invasiones enemigas, en mar, y en tierra. Lima: Casa de Julián Santos de Saldaña, por Jorge López de Herrera, 1647.

BENGOA, J. Historia de los antiguos mapuches del sur. Desde antes de la llegada de los españoles hasta las paces de Quilín. Santiago de Chile: Ed. Catalonia, 2003.

BERNEDO, P. Los industriales alemanes de Valdivia, 1850-1914. Historia, 1999, $\mathrm{N}^{\circ} 32$, p. 5-42.

BORRI, C. La expedición valdiviana de 1777 en busca de la "Ciudad de los Césares". Boletín Museo y Archivo Histórico Municipal de Osorno, 1995, No 2, p. 57-77.

CAMUS, P. Ordenamiento territorial y ferrocarril del sur en Osorno y Llanquihue. Revista de Geografía Norte Grande, 1997, $\mathrm{N}^{\circ} 24$, p. 165-174.

CAMUS, P. Ambiente, bosques y gestión forestal en Chile. 1541-2005. Santiago de Chile: Dibam-Lom, 2006.

DARWIN, C. Viaje de un naturalista alrededor del mundo. Buenos Aires: Librería El Ateneo, 1951.

DARWIN, C. Darwin en Chile (18321835) Viaje de un naturalista alrededor del mundo. Santiago de Chile: Editorial Universitaria, 1996.

DELORT, R. et WALTER, F. Histoire de l'environement européen. Paris: PUF, 2001.

DOMEYKO, I. 1802-1889. Memoria sobre la colonización en Chile. Santiago de Chile: Imprenta Julio Belin, 1850.

DONOSO, R. y VELASCO, F. Historia de la constitución de la propiedad austral. Santiago de Chile: Icira, 1928.

FELIÚ CRUZ, G. (Ed.). Relación del viaje de Hendrick Brouwer a Valdivia en 1643. Amsterdam, 1646. Versión castellana y pró- 
logo de José Toribio Medina. In: FELIú CRUZ, F. Opúsculos Varios de José Toribio Medina. Santiago de Chile: Fondo Histórico y Bibliográfico José Toribio Medina, 1926.

GLACKEN, C. Huellas en la playa de Rodas: naturaleza y cultura en el pensamiento occidental desde la Antigüedad hasta finales del siglo XVIIL. Barcelona: Serbal, 1996.

GONZÁLEZ DE AGÜERO, P. Descripción historial de la provincia y archipiélago de Chiloé en el reino de Chile y Obispado de Concepción dedicada a nuestro católico monarca don Carlos IV. Madrid: Imprenta de don Benito Cano, MDCCXCI.

GUARDA, G. Nueva Historia de Valdivia. Santiago de Chile: Ediciones Universidad Católica, 2001.

MARIÑO DE LOBERA, P. Crónica del reino de Chile. Santiago de Chile: Imprenta EI Ferrocarril, Colección de Historiadores de Chile, 1861.

OTERO, L. La huella del fuego. Historia de los bosques nativos. Poblamiento y cambios en el paisaje del sur de Chile Santiago de Chile: Pehuén, 2006.

PÉREZ ROSALES, V. Memoria sobre la colonización de la provincia de Valdivia. Valparaíso: Imprenta del Diario, 1852.

PÉREZ ROSALES, V. Ensayo sobre Chile. Santiago de Chile: Imprenta del Ferrocarril, 1859.

PÉREZ ROSALES, V. La colonia de Llanquihue, su origen, estado actual y medios de impulsar su progreso. Santiago de Chile: Imprenta de La Libertad, 1870.

PHILLIPI, R. Geografía de la Provincia de Valdivia. Revista del Pacífico, 1860, p. 624-625.
PHILLIPI, R. Valdivia en 1852. Revista de Chile, 1901, No 73, 74 y 75.

ROSALES, D. Historia general del reyno de Chile: Flandes indiano. Valparaíso: Imprenta del Mercurio Valparaíso, 1877 1878.

TREUTLER, P. Andanzas de un alemán en Chile, 1851-1863. Santiago de Chile: Editorial del Pacífico, 1958.

USAURO MARTÍNEZ, P. La verdad en Campaña. Relación histórica de la plaza, puerto y presidio de Valdivia. 1782. In: ANRIQUE, N. Biblioteca Jeográfico-Hidrográfica de Chile. $2^{\text {a }}$ serie. Santiago de Chile: Imprenta Elzeviriana, 1898.

VIDAL GORMAZ, F. Reconocimiento del río Valdivia i de las costa comprendida entre el Corral y Reloncaví. Anales de la Universidad de Chile, 1863, Tomo XXIII.

VIDAL GORMAZ, F. Reconocimiento del río Valdivia i de la costa comprendida entre Corral y Reloncaví. Memoria de Marina, 1870.

VIVAR, G. Crónica y relación copiosa y verdadera de los reinos de Chile. Berlín: Biblioteca Latinoamericana Ed. Colloqium Verlang, 1979.

WORSTER, D. Doing Evironmental History. In: WORSTER, D. The ends of the Earth. Perspectives on Modern Enviromental History. New York: Cambridge University Press, 1989, p. 290-291.

WORSTER, D. Natures Economy. New York: Cambridge University Press, 1977. Traducido al francés como Les pioners de l'ecologie. Une histoire de idées écologiques. Paris, 1992. 